\title{
SOMBRAS DEL CHILE ACTUAL UNA CONTRIBUCIÓN FILOSÓFICA
}

\author{
Enzo Solari A. - Samuel Yáñez A. ${ }^{1}$
}

SUMARIO: Introducción. Nuestro punto de vista. 1. (Neo) liberalismo y universalización. 2. El caso chileno: modernización sin modernidad (2.1.) Participación y democracia. (2.2.) Autoritarismo y cultura. Epilogo.

\section{INTRODUCCION}

Ya desde sus comienzos en la antigua Mileto, la actividad filosófica fue considerada por muchos un quehacer iluso e inútil. Podemos recordar, por ejemplo, a la criada de Heráclito, el Oscuro, explotando en carcajadas ante el espectáculo de su señor con el agua hasta el cuello, luego de haber caido en un pozo por estar investigando las estrellas. ¿Qué de bueno puede salir de un hombre que no sabe ni siquiera dónde se apoyan sus pies? Por ello, y ya desde antiguo, la actividad filosófica, junto con ofrecer sus aportes a la reflexión común de la humanidad, también ha debido justificar la necesidad y el valor de su contribución. ¿Qué puede decir la filosofía acerca de asuntos tan concretos como el modelo de desarrollo que se aplica en nuestro país, o acerca de la labor técnica de modernización del Estado? ¿No le faltará, acaso, un contacto más estrecho con los problemas reales de que se ocupan, por ejemplo, la psicología y la economía, tales como la ansiedad creciente de muchos espíritus, o el diseño de modelos que permitan incentivar un sostenido aumento de la riqueza? Por ello, pensamos que conviene, de modo breve, iniciar nuestra exposición con unas palabras acerca del sentido de nuestro aporte. Ello puede ayudar a apreciar mejor el carácter propio de una contribución filosófica a la consideración de estos problemas que a todos nos tocan.

Se puede decir, de modo general, que la historia de la filosofía es la historia de una pretensión intelectual muy alta, la de constituir un saber racional sobre las realidades que sea radical, universal y libre. Saber radical, porque no quiere quedarse en la superficie de los problemas, sino que busca conducir la reflexión hasta las raíces mismas de aquellos. La filosofia aspira a ser un saber de los principios. Saber universal, porque la búsqueda filosófica pretende un conocimiento de la totalidad

\footnotetext{
Los autores agradecen los comentarios y sugerencias que sus colegas CONTRERAS, Juan Pablo, GARCíA Diego y SILVA Eduardo hicieron a versiones preliminares de este trabajo. Y dejan constancia de que ésta es la yersión ligeramente corregida del comentario presentado en el Seminario de Profesores de la Universidad Alberto Hurtado sobre "El Chile actual y las tareas pendientes", en junio del 2001.
} 
de la realidad. Esto no significa conocer detalladamente cada parcela de realidad estos 'recortes' constituyen, justamente, el objeto propio de las ciencias naturales y sociales. Lo que la filosofia pretende es un saber unificador, capaz de dar sentido universal a todo específico saber humano. Por último, saber libre. Ya Platón sostenía que la dialéctica -ésa era su concepción del saber filosófico- es la ciencia de los hombres libres. ¿QQué significa esta libertad del saber filosófico?

Hoy nos resulta evidente, sobre todo por los aportes de las investigaciones sobre el lenguaje, que nuestras concepciones de la realidad cargan en su seno una multitud de supuestos de todo tipo -biológicos, psicológicos, sociales, culturales, religiosos, etc. Nuestra comprensión de la realidad se sirve del lenguaje, como medio de constitución, formulación y expresión. Y ya sabemos que toda lengua, cualquiera que ésta sea, incluso los llamados 'lenguajes formales', implican siempre supuestos y relaciones con determinadas 'teorías' y/o 'formas de vida'. Pues bien, aun asumiendo este ineludible dato, el saber filosófico se esfuerza por constituir un conocimiento que sea capaz de justificarse radicalmente a si mismo. En otras palabras, la filosofía aspira a ser un saber libre de supuestos o, al menos, levantado sobre supuestos justificables racionalmente y conocidos lúcida y críticamente. En este sentido, la historia de la filosofía puede interpretarse como la historia de la progresiva liberación de supuestos injustificados. Por esto, también, el saber filosófico rechaza todo dogmatismo y se mantiene abierto a la crítica y al diálogo racional. Esto no significa, por supuesto, el rechazo a priori de otras vías de conocimiento sobre la realidad, incluso superiores a la filosofía. La filosofía no pretende ser 'el' único saber. Su pretensión es más modesta, aunque no exenta de altura: constituir un saber racional radical y capaz de justificarse a sí mismo, libre de todo presupuesto indebido, sea religioso, cultural o ideológico. Su destino, la posibilidad de tal saber, tiene esencial relación con la posibilidad de realización de una vida humana racional de validez universal, lúcida sobre sí misma y crítica de toda forma de dominación irracional. Vivir como sujetos racionales, constituir una vida común sujeta a criterios razonables -capaz, por tanto, de superar la lógica de la violencia, del fanatismo y de la exclusión-, es un ideal íntimamente asociado a la posibilidad del saber filosófico. Aunque no se trata de algo que sólo incumba a la filosofía, es algo que no parece realizable sin el esfuerzo filosófico.

La tarea filosófica de constitución de un saber racional libre no se identifica con el ideal racionalista de orientar la vida humana mediante una 'pura' razón. Hoy somos conscientes de los límites de toda racionalidad. Sabemos que la razón tiene sus raíces en el mundo de la corporalidad y la afectividad, y no está separada de las experiencias histórica, estética y religiosa. No se trata, pues, de una razón todopoderosa. Con todo, sigue siendo verdad que la constitución de un desarrollo auténticamente humano pasa por el ejercicio siempre renovado de la racionalidad filosófica, autónoma, crítica y con pretensiones de radicalidad -aunque plenamente consciente de sus límites. 


\section{NUESTRO PUNTO DE VISTA}

¿Qué aporte pueden hacer a la consideración de los problemas humatios quienes se ejercitan en el establecimiento de un saber de tales características? Lo acabamos de ver. Por 'deformación profesional', el filósofo tiende a buscar los principios, tiende a considerar las cosas desde la totalidad, tiende, por último, a desenmascarar prejuicios y supuestos no debidamente justificados, desde el punto de vista racional. Éste, justamente, puede ser su aporte, y también constituye la limitación de su aporte. Así, por ejemplo, ante el modelo de desarrollo en curso en nuestro país, algunas preguntas 'filosóficas' podrían ser las siguientes. ¿Qué idea de 'desarrollo' porta el modelo en cuestión? ¿Está justificado razonablemente este concepto de desarrollo, es decir, es compatible con una adecuada idea de lo que sea el ser humano, su relación con el cosmos natural, etc? En suma, ¿se trata de auténtico desarrollo humano?

Puede mencionarse también otro tipo de interrogantes 'filosóficos'. La idea cosmopolita de la humanidad, la idea de que la humanidad es una sola y forma una sola sociedad, se manifestó ya en la época helenista, con el desarrollo de las concepciones estoicas, que tanto influyeron en la ideología del Imperio Romano, Más cerca de nosotros, esta idea también alcanzó desarrollo gracias a los ideales de la ilustración europea. Pero, así parece, sólo en nuestros dís dicha idea ha alcanzado empírica realización. Efectivamente, lo que sucede en algún lugar del mundo tiene repetcusiones en los modos concretos de vida en otro lugar del planeta. Podemos pensar, por ejemplo, en la llamada 'crisis asiática', en el actual esfuerzo por constituir un tribunal penal internacional, o en las características comunes que tienden a homogeneizar la vida cotidiana de los habitantes de las grandes urbes. Si es así, entonces toda pregunta por un determinado y particular modelo de desarrollo -por ejemplo, el modelo que se implementa en Chile- debe hacerse desde una comprensión del modelo global donde este proyecto particular se inserta. Más aún, la evaluación moral de dicho modelo debe referirse, también, a las posibilidades que ofrece para el desarrollo universal de la vida humana, a escala planetaria. Si los procesos son globales, si las consecuencias son globales, entonces el principio de universalización forma parte ineludible del juicio ético. Esto ya lo veía Kant a fines del siglo XVIII. Preguntemos, entonces, ¿es universalizable 'nuestro' modelo de desarrollo? ¿Son universalizables las condiciones materiales, sociales, económicas, políticas y culturales que están a la base del desarrollo del modelo capitalista, es decir, nuestras maneras de producir, de consumir, de resolver nuestros problemas, etc.? ¿Puede la humanidad, globalmente, alcanzar este 'modo de vida'?

Por último, podemos formular preguntas dirigidas en otra dirección. Desde la perspectiva de la totalidad, ¿resulta coherente el modelo desde sus distintos puntos de vista, a saber, el económico, el político, el cultural? Lo que se asienta 
como principio en un ámbito, ¿vale también para los otros? ¿O, más bien, se defiende en Chile una economía de mercado libre, junto con una convivencia política restringida, en medio de una sociedad que reprime de muchos modos la autonomía cultural del individuo y de los grupos? El discurso legitimador, ¿no resulta también encubridor?

La presentación que hacemos consta de dos partes. En primer lugar, nos haremos algunas preguntas sobre el modelo capitalista de desarrollo hoy triunfante. ¿Es universalizable este modelo? ¿Se trata, efectivamente, de un modelo de libre mercado? En segundo término, abordaremos dos aspectos sugerentes de nuestra realidad nacional: la participación democrática, y lo que podriamos llamar el 'inquilinaje' cultural. La primera parte tiene en consideración que 'nuestro' modelo de desarrollo tiene que entenderse en el contexto de la situación global de la humanidad. En cambio, en la segunda parte nos dedicamos a aspectos más propios de nuestra idiosincrasia nacional. El hilo conductor de toda la presentación, la perspectiva propiamente filosófica de este trabajo, se expresa en el concepto de universalidad. Se trata, a la vez, de un criterio de realidad y de una exigencia moral. En ambos sentidos, va intimamente asociado a la noción de una básica igualdad entre todos los seres humanos.

La contribución filosófica no es técnica, en el sentido de dar soluciones concretas a problemas concretos. Se trata, más bien, de formular preguntas que nos permitan conocer con más profundidad lo que analizamos, en este caso, el Chile actual y las tareas pendientes. Estas preguntas pueden revelarnos aspectos desconocidos, no pensados ni reconocidos aún. Pueden llevarnos a pensar más, tal vez a pensar de otro modo. Pueden hacer nacer en nosotros nuevas inquietudes. ¿Cómo, después, llevar esto a la práctica? Ya se verá. Lo primero es tomar conciencia del asunto, lo más lúcida y profundamente que se pueda. Ello hará posible una acción más responsable y autónoma, más sabía. Tal vez, y eso ya sería un gran fruto, terminemos por dudar un poco del 'cuento' que nos contamos.

\section{1. (NEO)LIBERALISMO Y UNIVERSALIZACIÓN}

Evidentemente aquí no desarrollaremos -ni de lejos- una adecuada caracterización tecnológica, económica, social y cultural de esta época, la del triunfante capitalismo informacional en $\mathrm{red}^{2}$. Nos conformaremos con algunas anotaciones críticas que-pensamos-tienen fundamentum in re.

Una de las críticas recurrentes al modelo capitalista enfatiza las enormes desigualdades que éste produce, ricos cada vez más ricos y pobres cada vez más

\footnotetext{
${ }^{2}$ Para orientarse, vid. CASTELLS, Manuel, La era de la información. Economia, sociedad y colltura la sociedad red (trad, C. Martinez, Siglo XXI Editores, México-Madrid 1999), 590 pp. Más en particular, respecto del neoliberalismo y de las críticas a las que ha sido sometido, vid. VV.AA., "Neoliberalismo: propuestas y contrapropuestas", en Persona y Saciedad 13 (1999) 2, $271 \mathrm{pp}$.
} 
pobres, tanto al interior de los Estados nacionales como a escala planetaria. Esta desigualdad creciente no constituye un aspecto marginal al sistema, sino que parece formar parte de su estructura íntima.

"El ascenso del informacionalismo en este fin de milenio va unido al aumento de la desigualdad y la exclusión en todo el mundo... El proceso de reestructuración del capitalismo, con su lógica fortalecida de competitividad económica, tiene mucho que ver con ello...

El ascenso del capitalismo informacional global se caracteriza por el desarrollo y subdesarrollo económico simultáneo y la exclusión e inclusión sociales, en un proceso reflejado en líneas generales en las estadísticas comparativas. Existe polarización en la distribución de la riqueza a escala global, una evolución diferencial de la desigualdad de la renta en el interior de los países y un aumento sustancial de la pobreza y la miseria en el mundo en general y en la mayoria de los países, tanto desarrollados como en vias de desarrollo... He tratado de mostrar... el complejo conjunto de vinculaciones que existen entre las caracteristicas del capitalismo informacional y el aumento de la desigualdad, la polarización social, la pobreza y la miseria en la mayor parte del mundo. El informacionalismo crea una aguda divisoria entre pueblos y localidades valiosos y sin valor. La globalización avanza de forma selectiva, incluyendo y excluyendo a segmentos de economías y sociedades dentro y fuera de las redes de información, riqueza y poder que caracterizan al nuevo sistema dominante... Pero en este proceso de reestructuración social hay más que desigualdad y pobreza. También hay exclusión de pueblos y territorios que, desde la perspectiva do los intereses dominantes en el capitalismo informacional global, pasan a una posición de irrilevancia cultural. Este amplio y multiforme proceso de exclusión social lleva a la formación de lo que denomino... los agujeros negros del capitalismo informacional. Son las regiones de la sociedad desde las que, bablando estadisticamente, es imposible escapar al dolor y la destrucción infligidos sobre la condición bumana de quienes, de un modo u otro, entran en estos paisajes sociales...

[Este Cuarto Mundo no sólo africano, asiático y latinoamericano sino también presente -aunque de otra manera- en Norteamérica, Europa occidental y el Asia del pacífico] está habitado por millones de personas sin techo, encarceladas, prostituidas, criminalizadas, brutalizadas, estigmatizadas, enfermas y analfabetas. Son la mayoría en algunas zonas, la minoría en otras, y una exigua minoría en unos pocos contextos privilegiados. Pero, en todas partes, su número aumenta y son más visibles, a medida que el criterio selectivo del capitalismo informacional y la quiebra política del Estado de bienestar intensifican la exclusión social. En el contexto histórico actual, el ascenso del Cuarto Mundo es inseparable del ascenso del capitalismo informacional global.",

Las consecuencias económicas, psicosociales y políticas de la desigualdad -lo feconoce el sentido común y lo confirman investigaciones de muy diverso tipo- son

CASTE1.IS, Manuel, I a eni de la informución. Economia, sociedad y caltura: fin de milenio (trad. C. Martinez, Siglo XX7 Editores, México-Madrid 1999), pp. 97, 107, 188, 189 y 191. Vid. también GONZÁLEZ, Antonio, "Orden mundial y liberación". en Fstudios Centroamericanos 543-544 (1994), p. 630), 
desoladoras ${ }^{4}$. Y son enormemente sintomáticas de un orden económico mundial cuyas prácticas se apartan con frecuencia de los postulados liberales (pese a que se repita una y otra vez que la ideología legitimadora del sistema es el liberalismo) $)^{5}$, además, de un orden caracterizable como un modelo de dominación material y simbólica de quienes poseen el capital y la información.

"En todos los países avanzados, empresarios, altos funcionarios internacionales, intelectuales mediáticos y periodistas de alto vuelo se han puesto de acuerdo en hablar una extraña neolengua cuyo vocabulario -aparentemente surgido de la nada- está en todas las bocas: 'mundialización' y 'flexibilidad'; 'gobernabilidad' y 'empleabilidad'; 'underclass' y 'exclusión'; 'nueva economía' y 'tolerancia cero'; 'comunitarismo', 'multiculturalismo' y sus primos 'posmodernos': etnicidad, minoría, identidad, fragmentación, etc. De esta nueva vulgata planetaria están notoriamente ausentes términos como capitalismo, clase, explotación, dominación y desigualdad, perentoriamente anulados bajo pretexto de obsolescencia o de presunta impertinencia. Su difusión es producto de un imperialismo propiamente simbólico; sus agentes transmisores son los partidarios de la revolución neoliberal: escudándose en la 'modernización' piensan rehacer el mundo haciendo tabla rasa de conquistas sociales y económicas, producto de cien años de luchas sociales, actualmente presentadas como otros tantos arcaísmos y obstáculos al nuevo orden naciente; pero también productores culturales (investigadores, escritores, artistas) y militantes de izquierda que, en su gran mayoria, se siguen considerando progresistas; lo cual hace que sus efectos sean aún más potentes y perniciosos...

La insistencia mediática transforma en sentido común universal esos lugares comunes mundializados en el sentido estrictamente geográfico, a la vez que desparticularizados. Lugares comunes que logran hacer olvidar que habitualmente sólo expresan -bajo una forma truncada e irreconocible, incluso para quienes los propagan- las realidades complejas y controvertidas de una sociedad histórica particular, tácitamente constituida en modelo y en medida de todas las cosas: la sociedad estadounidense de la era posfordista y poskeynesiana. Esa superpotencia única, esa Meca simbólica de la Tierra, se caracteriza por el deliberado desmantelamiento del Estado social y por el correlativo hipercrecimiento del Estado penal; por el aplastamiento del movimiento sindical y por la dictadura de la concepción empresaria, fundada sólo en el 'valor accionario', y por sus

\footnotetext{
4 Para el caso chileno, vid. VV.AA., "¿Puede la desigualdad esperar?", en Rocinante 29 (2001), pp. 32-36, y GONZÁLEZ, Raúl, "Equidad para superar la pobreza", en Mensaje 497 (2001), pp. 45-48. Ambos son textos que responden a LEHMAN, Carla y HINZPETER, Ximena, "Los pobres no pueden esperar; la desigualdad, sí....", en Puntos de referencia 233 (2000), 12 pp. Vid. también BENGOA, José, MÁRQUEZ, Francisca y ARAVENA, Susana, La desiggralkad (Ediciones SUR, Stgo. de Chile 2000), 338 pp.

GONZȦLEZ, Antonio (n. 2), pp. 642-643.
} 
consecuencias sociológicas: la generalización del trabajo asalariado precario y de la inseguridad social, constituida en motor privilegiado de la actividad económica... ",

Debe agregarse que el poder económico sustantivo de los países desarrollados reside cada vez menos en el aparato estatal con controles democráticos, quedando más bien asentado en gigantescos consorcios transnacionales. En su reciente visita a nuestro país, el Premio Nobel de Literatura 1998, el portugués José Saramago, comentaba que en un reciente encuentro de escritores en Norteamérica, uno de ellos bromeaba en el sentido de que Bill Clinton era el último presidente de los EE.UU. -los megaintereses económicos ya no necesitarían de la mediación del poder político.

Casi resulta obvio, además, mencionar el gravísimo daño ambiental que produce el modelo capitalista de desarrollo.

"La destrucción de la capa de ozono, el efecto invernadero, la contaminación de las aguas, la desertización y la deforestación, la desaparición de la flora y fauna, etc., son problemas de alcance global tanto por sus orígenes como por sus efectos... La gravedad de la crisis ecológica pone en entredicho tres de los grandes mitos de la era moderna. En primer lugar, el mito de la soberanía de los estados: una respuesta adecuada a una crisis que es global requiere adoptar medidas que forzosamente sean globales, y que por tanto se han de aplicar constriñendo de algún modo los intereses y las opciones a corto plazo de cada Estado, especialmente de los más industrializados. En segundo lugar, se desmorona el mito del crecimiento continuo de las economías. Si todos los habitantes del globo vivieran según los patrones de consumo habituales en los países industrializados, la vida sería imposible sobre el planeta ${ }^{7}$.. La pobreza en el planeta tiene un carácter estructural, aunque no siempre hubiera explotación, por razones puramente ecológicas y de recursos. Finalmente, la crisis ecológica desmiente el mito del mercado como solución universal: preservar el medio ambiente supone sacrificar alternativas económicas rentables a corto y medio plazo, y esto no se hará si no hay algún tipo de constricción al mercado, que forzosamente ha de ser global por serlo el problema planteado."

El modelo, por ende, no parece resultar universalizable en términos materiales. A no ser que se piense, expresa o implícitamente, incluso sin quererlo ni darse cuenta de ello, en mantenerlo por la vía de la perpetuación de las desigualdades. Quizá en este sentido habría que interpretar las reflexiones de Apel y Habermas. Para ellos, una norma es éticamente aceptable si todos los actual o virtualmente afectados por ella pudiesen aceptarla, exentos por cierto de cualquier coacción. Esto es, la validez moral depende de la afirmación expresa o tácita de los

\footnotetext{
"BOURDIEU, Pierre y WACQUANT, Loic, "Una nueva vulgata planetaria", en Le Monde Diplomatigue 11 (2000), p. 12.

${ }^{7}$ ¿Qué pasaria, por cjemplo, si dichos patrones de consumo fueran asumidos tan sólo por los habitantes de China? 8 GONZALLEZ, Antonio (n. 2), pp. 643-644.
} 
presupuestos envueltos en toda clase de argumentación, a falta de los cuales tal comunicación lingüística se vuelve imposible. Esto es así, sea que tales presupuestos se piensen como condiciones trascendentales constitutivas de una comunidad ideal de comunicación, sea que se trate de condiciones empíricamente presentes en los diversos mundos de vida. Ignacio Ellacuría y Antonio González, rescatando el valor de la escuela de Frankfurt, sin embargo destacan sus limitaciones. En palabras de Ellacuría:

“... La oferta de humanización y de libertad que hacen los países ricos a los países pobres no es universalizable y, consiguientemente, no es humana, ni siquiera para quienes la ofrecen. El agudo planteamiento de Kant podría aplicarse a este problema: 'obra de tal modo que la máxima de tu voluntad pueda valer siempre, al mismo tiempo, como principio de una legislación universal' (Crítica de la razón práctica).

Si el comportamiento y el ideal de unos pocos no puede convertirse en comportamiento y en realidad de la mayor parte de la humanidad, no puede decirse que ese comportamiento y ese ideal sean morales, y ni siquiera humanos; cuánto más, si el disfrute de unos pocos se hace a costa de la privación de los más... El ideal práctico de la civilización occidental no es universalizable, ni siquiera materialmente, por cuanto no hay recursos materiales en la tierra para que todos los países alcanzaran el mismo nivel de producción y de consumo, usufructuado hoy por los países llamados ricos, cuya población no alcanza el $25 \%$ de la humanidad.

Esa universalización no es posible, pero tampoco es deseable. Porque el estilo de vida propuesto en y por la mecánica de su desarrollo no humaniza, plenifica ni hace feliz, como lo demuestra, entre otros índices, el creciente consumo de drogas, constituido en uno de los principales problemas del mundo desarrollado. Ese estilo de vida está movido por el miedo y la inseguridad, por la vaciedad interior, por la necesidad de dominar para no ser dominado, por la urgencia de exhibir lo que se tiene, ya que no se puede comunicar lo que se es. Todo ello supone un grado mínimo de libertad, y apoya esa mínima libertad más en la exterioridad que en la interioridad. Implica asimismo un máximo de insolidaridad con la mayor parte de los seres humanos y de los pueblos del mundo, especialmente con los más necesitados."

González, por su parte, destaca que el adversario de la ética discursiva parece ser solamente el escéptico; es él quien no puede entrar verazmente en un discurso sin presuponer ciertas condiciones mínimas, gracias a las cuales ese discurso se puede llevar a cabo. Empero, el cínico no resulta tocado por esta reflexión, pues no entra verazmente en la comunicación: sólo lo hace interesada y propagandísticamente. ¿Cómo negar la presencia de posiciones cínicas en muchos diálogos desarrollados en medio de todas las complejidades históricas? Pero hay

ELLACURIA, Ignacio, "Utopía y profetismo", en Mysterium Liberationis (Trotta, Madrid 1990) 1, pp. 406-407. 
más, según González. La ética discursiva está montada sobre el nivel de vida y desarrollo de las nacionales más industrializadas del planeta, "pues sin ese nivel de vida no tendriamos las condiciones minimas de posibilidad para resolver democráticamente los problemas bumanos". Mas, tal nivel de desarrollo no es universalizable: su universalización ocasionaría una catástrofe ecológica.

"De ahi [Apel] concluye que los pueblos del Tercer Mundo, en lugar de pretender alcanzar los niveles de vida occidentales, deberían de contentarse con aspirar a una vida suficientemente digna, que no choque con los límites ecológicos del planeta. Ahora bien, ante la imposibilidad de universalizar los niveles de vida occidentales, un kantiano como Apel debería haber pensado que esos niveles de vida son éticamente reprobables, Si no lo hace, no es por mala voluntad, sino por un límite propio de toda ética del discurso. El diálogo generalizado presupone el nivel de vida alcanzado por las sociedades industrializadas... Pero Apel mismo reconoce que ese nivel de vida no puede alcanzar a toda la humanidad. Y esto significa que el diálogo contiene presupuestos que no son universalizables. Por eso, las éticas del discurso no pueden poner en entredicho la corrección ética del nivel de vida occidental sin caer en una 'contradicción performativa', consistente en negar las condiciones de posibilidad del propio discurso." "1t

El modelo, pues, a la luz de estas consideraciones, resulta moralmente inaceptable. No sólo por razones 'valóricas', sino debido a un razonable principio de realidad -que resulta ser un criterio ético insoslayable. ¿Debemos apresurarnos tanto, entonces, a 'subirnos al carro de la modernización'? ¿No será más razonable 'llevar un pie fuera', ya que no es posible todo el cuerpo, buscando apasionadamente vías con mejor futuro?

Pensando en el futuro, chay algo que hacer? ¿O, como también decía Saramago, lo único que queda es musitar "¿a dónde nos llevan?".

"La caída del bloque socialista no sólo ha corroborado las dificultades internas de las economías estatalizadas, sino que además constituye para los pueblos pobres el punto final de una estrategia de liberación cuyo eje era la conquista del poder político del Estado. Esto no es, en sí mismo, ninguna confirmación de la bondad del sistema capitalista, pues los problemas estructurales de la pobreza, la desigualdad económica y la injusticia social siguen vigentes e incluso se agravan. Los movimientos de liberación están adoptando, en esta situación, nuevas estrategias de lucha, en las que lo local y lo global se entrelazan, al mismo tiempo que lo estatal adquiere una función más bien complementaria. La sociedad civil global, y las estrategias que en ella aparecen (como la nueva economía popular), adquieren una importancia decisiva. La perspectiva de una sociedad mundial ya existente permite que tales luchas se funden, no en apelaciones a los sentimientos

10) GONLÁLE'L, Antonio, Estnicturas de la praxis (Trotta, Madrid 1997), p. 178.

11

GONZÁLEZ, Antonio (n. 9), p. 178. 
solidarios o caritativos de los más poderosos, sino en la exigencia de unos derechos que les corresponden a todos. Por ello, el fin de ciertas estrategias no disminuye la radicalidad y urgencia de la lucha, sino que en realidad la aumenta. Y es que no se trata solamente de resistir al imperio, de salirse de él, o de pasarse a un imperio concurrente. Se trata más bien de transformar internamente el único imperio existente, en el que estamos.,"12

Sin embargo, hay que reconocer que cualquier intento de transformación del actual capitalismo enfrenta serias dificultades. Sobre todo por el carácter 'inevitable', 'indiscutible' de la nueva economía globalizada con todas las consecuencias que la acompañan. Por eso, la llamada 'naturalización de lo social' es hoy casi un lugar común de la crítica anticapitalista, como en el caso de Moulián, entre nosotros $^{13}$. Mas, no deja de advertirse la dificultad teórica de esta crítica. Es lo que piensa Lechner: "en realidad, no disponemos de estudios que desentrañen la economia politica del desarrollo capitalista en su fase actual. Este déficit teórico limita seriamente las 'críticas' al modelo imperante."

En suma: son numerosas y poderosas las razones que pueden esgrimirse para poner en tela de juicio el capitalismo al cual las élites nacionales -e importantes sectores de la población chilena- parecen haber adherido. Sin embargo, hay que reconocer simultáneamente los muchos factores conceptuales y materiales que hacen enormemente dificultosa su transformación.

\footnotetext{
${ }^{12}$ GONZȦLEZ, Antonio (n. 2), p. 650.

${ }^{13}$ El mismo Castells se ha referido a esta naturalización de las desigualdades tan tipica del capitalismo de la información: "La miseria y la exclusión no se modificarán a menos que haya un cambio en las leyes que gobiernan el universo del capitalismo informacional, ya que, a diferencia de las fuerzas cósmicas, la acción humana deliberada puede cambiar las reglas de la estructura social, incluidas las que inducen la exclusión social": CASTELLS (n. 2), p. 189.

LECHNER, Norbert, "El loro de Flaubert y el búho de Minerva", en Rocinante 28 (2001), p. 12. Con todo, Lechner aventura una interpretación teórica de la naturalización de lo social, a la zaga de Durkheim y sus ideas acerca de la 'sacralización de los fundamentos del orden social': 'T a sociedad requiern imaginarios colectivos gue represenlen un 'nosolros' $y$ tiende a garantizar las normas constitutius de esa vida en comin como algo sagrado fuera de ella. Este fenómeno podría ser la clave para interpretar la natumalizacioin de lo social. Convidero la naturalización como una forma de sacralización. Compensando la 'econificación' del Estado, el merado adquiere un halo sagrado. La experiencia cotidiana nos enseria que el mercado es 'algo' más que solamente tun mecanismo de coordinación social que - 'mano invisible' mediante- regula las relaciones entre los individuos. Me parece que la 'lógica del merato' representa aquella instancia sacrosanta que simboliza el principio comin que integna nuestra contritencia diaria. Y la sacralización de esa logica conlleva ta exdusión de sus elementos básicos - camo el equilibrio macroconómico y los criterios de flexibilización, productividad y ampetitividad de la disczsión social. De este moda las leyes del meraado quedan investidas de la autoridad necesaria para justificar los costos sociales y regular (y de ser necesario disciplinar) La interación social: p. 13.
} 


\section{EL CASO CHILENO: MODERNIZACIÓN SIN MODERNIDAD}

\subsection{Participación y democracia ${ }^{15}$}

Últimamente, Adela Cortina ha auspiciado una democracia radical basada en lo que Kant denominaba 'uso público de la razón'. Aquí, la democracia no es entendida como modelo mercantil ni está basada en individuos puramente privados y autointeresados, sino que es un régimen (1) cuya legitimidad radica en la defensa comunicativa y autónoma de intereses universalizables y (2) que se caracteriza por suponer y promover una ciudadanía con alto nivel de asociatividad y que influya en el poder político a partir de una 'publicidad razonante'.

En este sentido, la cuestión de la participación democrática no se agota ni se plantea correctamente sólo dentro de los marcos del sistema político, sino que puede y debe prolongarse -allende el aparato público-estatal- en la sociedad civil y en la ciudadanía. Lo más verdadero de la participación democrática apunta a la política en un sentido amplio y radical, sin olvidar que es posible una mayor democratización de las democracias liberales -piénsese, por ejemplo, en la incorporación de mecanismos de democracia directa. Entre el mercado y el Estado hay un tercer sector. Sus protagonistas no son solamente consumidores ni votantes, sino ciudadanos. La reflexión cívica, ciudadana es muy relevante en estos días. La misma Cortina dirige su reflexión hacia una ciudadanía a la altura de los tiempos, incluyente de la justicia (veta liberal) y de la pertenencia (veta comunitaria), ciudadanía tanto política y social como económica, civil e intercultural. Los valores cívicos para educar en la ciudadanía son la libertad, la igualdad, el respeto activo, la solidaridad y el diálogo. Esta ciudadanía contemporánea, termina Cortina, ha de ser cosmopolita. Tal tipo de reflexión es compartido por distintos autores. Así, Peter Berger ha hablado de potenciar (empowver) al ciudadano para fortalecer la propia vida democrática y política. Dicho fortalecimiento ciudadano supone favorecer el papel de las instituciones intermedias, como el barrio, la familia, las iglesias y las asociaciones voluntarias. De todos modos, esta estrecha vinculación entre ciudadanía y democracia no debe ocultar el valor intrínseco de la sociedad civil ni de la acción asociada. En el fondo, hoy día se percibe que la política no está restringida a los cauces regulares de los órganos estatales sino que se desarrolla a muy distintas escalas por parte de muy diversos sujetos individuales y colectivos. La ciudadanía es valiosa por sí misma y no sólo por su funcionalidad democrática. Es un espacio de acción y participación y un productor y reproductor de sentido e identidad. Un caso límite de este concepto ampliado de ciudadanía -más allá del

\footnotetext{
15 En este apartado reproducimos y sintetizamos algunas reflexiones de SOJ_ARI, Enzo y GARCIA, Diego, "El malestar constitucional chileno", en Persona y Sociedad 14 (2000) 3, pp. 7-26, y en Anuario de Filosofía Juridica y Social 18 (2000), pp. $499-533$.
} 
ejercicio de los derechos políticos- es el de los menores de edad y la infancia, respecto de quienes se emplea progresivamente la expresión 'ciudadanos' no obstante no ser titulares de los derechos políticos.

$\mathrm{Si}$ volvemos desde estas consideraciones al caso chileno, tenemos mucho que pensar y que hacer. Un botón de muestra. Se ha sugerido invertir la tesis de A. Pinto, según la cual Chile -antes del golpe de 1973- era un caso de subdesarrollo económico y superdesarrollo político; en la actualidad, en Chile habría un importante desarrollo económico y un considerable subdesarrollo político ${ }^{16}$. Mas, ¿de qué política se trata? Este es un asunto importantísimo. Se trata de los desafíos políticos que enfrenta la sociedad civil entre nosotros. El último Informe del PNUD en Chile -el del año 2000, como ya se dijo- aborda esta cuestión. Su título es sintomático: Más sociedad para gobernar el futuro. Este informe postula que en el nuevo contexto nacional e internacional, caracterizado por la globalización, la individualización y la persistencia de las identidades colectivas, las tareas que se nos presentan -vinculadas con nuestra democracia, nuestro crecimiento económico y nuestra integración social-implican una sociedad 'fuerte', 'densa', cualitativamente desarrollada. Por sociedad fuerte entiende este Informe una sociedad en la cual las personas tiendan a ser los sujetos y los beneficiarios del desarrollo. Para que tal cosa comience a verificarse, la calidad de la vida social de los chilenos, actualmente deficitaria, tiene que mejorar. En este sentido, el informe toca tres áreas 'críticas': las aspiraciones o sueños colectivos, el capital social y la asociatividad y, por fin, la ciudadanización de la política. Su tesis es que hay una correlación positiva -un 'triángulo virtuoso'- entre estas tres áreas ${ }^{17}$. Y, sin embargo, a propósito de la ciudadanía, el mismo informe constata un panorama ambivalente ${ }^{18}$. De todos

\footnotetext{
16 "

"Chile parece sufrir nuevamente una especie de desequilibrio, existiendo ahora un 'déficit' de politica en relación a la modernización económica... Mientras que ei régimen autoritario se caracterizó por una 'modernización sin modernidad', el régimen democrático conlleva la promesa de conducir el proceso de modernización acorde a la voluntad mayoritaria. Entonces se hace evidente la paradoja del desarrollo chileno: la modernización económica del país remite a la elaboración democrática de opciones y decisiones acerca del desarrollo en el momento mismo en que la democracia ve restringida la capacidad política de conducir el desarrollo... A mi juicio, Chile, al igual que otros paises de América Latina, enfrenta el siguiente dilema: responder simultáneamente a las exigencias de la modernización y de la democratización, siendo que los dos procesos obedecen a racionalidades diferentes, cuando no contrapuestas": LECHNER, Norbert, "Modernización y democratización: un dilema del desarrollo chileno", en Estudios Públicos 70 (1998), pp. 233, 236 y 241.

17

Vid. PNUD, Informe de Desarrollo Humano en Chile 2000: Más sociedad para gobernar el futuro, pp. 57-210. "La ciudadania opera, pues, como una especie de 'convertidor' que traduce las aspiraciones de las personas y sus recursos 18 asociativos en acción política": PNUD, Informe de Desarrollo Humano en Chile 2000. Sinopsis, p. 20.

De un lado debilidades, como nuestra defectuosa institucionalidad política, la baja inscripción en los Registros Electorales, la alta abstención electoral, la desafección politica, la menor participación de jóvenes y mujeres, una desigual valoración de la democracia y otros más. Sin embargo, se aprecia tambièn que más de la mitad de las personas entrevistadas en profundidad estima que "puede hacer mucho para cambiar la marcha del país"; estas personas son también las que mayor participación política exhiben y las que más se representan el orden social de modo pluralista. Asimismo, se percibe una reconstrucción de la ciudadania, ya no tan ligada con las instituciones políticas formales, sino más coludida con la convivencia social y las aspiraciones colectivas. A la pregunta por el sentido más significativo de ciudadanía ("cun ciudadano es alguien que...?"), se responde asi: un $2 \%$ no sabe o no responde, un $11 \%$ menciona una ciudadanía patriótica ("jura lealtad a la patria"), un $13 \%$ una ciudadanía electoral ("va a votar"), un $32 \%$ indica una
} 
modos, más que un quehacer de profesionales, la política parece estar significando cada vez más un ejercicio ciudadano vinculado con los sueños sociales y la calidad de la vida colectiva. A la vez, según el informe es indispensable que la política formal se vuelque a la sociedad y que la sociedad entre de alguna manera en dicha política $^{19}$.

En fin: parece necesario realizar en Chile un ejercicio de discernimiento público. El malestar constitucional y político está más presente que nunca. Después de diez años de una democracia aún no consolidada, hemos vivido entre las amenazas de unos, la impudicia de otros y el realismo estratégico de otros más. Dejando a un lado la ciudadanía, quizá ya sea hora de pensar, ya no en una que otra reforma constitucional, sino en una nueva Constitución ${ }^{20}$. ¿No ha llegado, tal vez, el momento en que las élites políticas y académicas emprendan una deliberación libre, razonable, abierta y responsable ante los ciudadanos- en vistas de un nuevo texto constitucional?

\subsection{Autoritarismo y cultura}

Queremos añadir una palabra sobre un aspecto de nuestra idiosincrasia cultural. Entre los rasgos característicos de la chilenidad, suelen indicarse buenas dosis de conservadurismo, de autoritarismo y de tendencias racistas, tanto ad intra ('rotos', 'indios') como ad extra (¿jpor qué no queremos ser latinoamericanos?).

ciudadanía legal ("cumple con las leyes del pais") y un 42"\% afirma una ciudadania activa ("se siente responsable por el 19 rumbo que tome el país o participa activamente en los asuntos de la comunidad”).

9 "Habria una relación circular: una sociedad fuerte, capaz de generar aspiraciones y vínculos sociales, promueve una ciudadanización de la política; $y$, a la inversa, la acción ciudadana apunta al fortalecimiento de la trama social. Ello desafia el modo en que funciona el sistema político. Por una parte, convendría 'salir a lo social', reconocer y estimular las fortalezas de la sociedad, incentivar la acción ciudadana. Por otra, el sistema político deberia 'dejar entrar lo social', invitar a lo público a manifestarse y escuchar las claves de la conversación social. Este proceso de aprendizaje permitiria aprovechar las oportunidades que ofrece la ciudadanización y evitar el riesgo de irrupciones populistas": Sinopsis (n. 16), p. 22 .

20

A lo menos, existen tres graves contradicciones en el conjunto del entramado constitucional chileno: 1) Al interior del régimen politico, entre los principios de un régimen democrático sustentado en una afirmación de la nación como titular de la soberania, máximo poder político del Estado, subordinada de todos modos al respeto de los derechos humanos, por una parte, y la permanente tutela militar sobre el sistema politico, por la otra. 2) Al interior de las normas constitucionales relacionadas con el orden público económico y la acción económica, entre los principios de un Estado social de derecho que prescrabe al Estado ciertas acciones positivas a favor de los más débiles y en beneficio de una mayor igualdad de oportunidades, por una parte, y un orden de mercado con la menor intervención empresarial y subsisdiaria del Estado, en el que el óptimo social está dado por la asignación de recursos que resulte del libre juego de las fuerzas del mercado, aunque de ello derive una muy desigual concentración del poder económico en pocas manos. 3) Bajo el supuesto de que opera un consenso en torno a democracia politica y economía de mercado, cabe apuntar entonces una gravísima contradicción constitucional entre el principio democratizador (descentralización del poder) y el principio del mercado desreguiado (concentración del poder económico como pretendido óptimo social). Pero, además de las tutelas, contradicciones y restricciones examinadas, hay que recordar que las cuestiones olvidadas, desfiguradas o apenas entrevistas por la CCh son legión: la protección del ambiente y su relación con el crecimiento económico y el desarrollo humano, los pueblos originarios, la situación de las minorias de todo tipo, la globalización económica y de la información, la modernización de la gestión estatal y la accountability, los mecanismos de democracia directa, la libertad de expresión, una regionalización real y sustantiva, etc. Sin olvidar que la CCh surgió en un régimen autoritario y que fue aprobada a través de un plebiscito irregular. 
Algunos han observado la relación que esto tendría con una cierta pervivencia del inquilinaje en la cultura chilena: las nuestras serían relaciones sociales caracterizadas casi congénitamente por el despotismo y la sumisión: ${ }^{21}$. Anécdotas como la de la empleada doméstica que no pasa a la mesa de los patrones, ni aun el día de su cumpleaños, reflejan problemas culturales derivados de la matriz patrón-inquilino: el sueño emancipatorio del inquilino termina en tener 'buenos patrones que le apadrinen la guagua'. Como decía algún $1^{\circ}$ de noviembre una señora que trabaja arreglando tumbas en el Cementerio General, "hay que votar por los ricos porque ellos nos dan trabajo".

Tal vez, la última expresión de nuestro 'inquilinaje' cultural la constituya la emergencia social y política de las preocupaciones policiales.

“... En el Chile de los ochenta se produjo una revolución restauradora. No pareciera que se haya generado una suerte de revolución capitalista empresarial hacia delante. Un real proceso de modernización societal, entendido éste como ampliación de la ciudadanía, democratización de derechos cívicos y económicos, consolidación de una cultura simbólicamente igualitaria. No surge de este proceso una sociedad moderna y liberal con capacidad integradora, sino una profundamente conservadora y estamental. Las clases adineradas se atrincheran en sus barrios, colegios, universidades, hospitales y clínicas, construyendo un sistema de reproducción cerrado en sí mismo. Los estudios acerca de desplazamientos en la ciudad muestran que una enorme cantidad de personas no cruza las fronteras, ya no simbólicas sino materiales, que separan los mundos urbanos. Hay áreas que la policía ha decretado de 'alto riesgo' y que coinciden con la pobreza, la marginalidad y la exclusión. El mapa de la exclusión va de la mano con el mapa de la seguridad ciudadana. La 'doctrina de la seguridad ciudadana' vino a reemplazar la doctrina de la 'seguridad nacional'. Loreto Hoecker ha demostrado, sobre la base de un estudio pormenorizado de los editoriales del diario El Mercurio, la manera como se fue construyendo esta doctrina. Es un proceso de 'instalación' de un discurso de 'inseguridad'. Sin que la población lo perciba, el asunto comienza a aparecer natural, consensual y obvio. Hay áreas de riesgo, personas que son 'sospechosas', ámbitos de la población que ponen en peligro al conjunto de la sociedad. Se pone el tema de la 'seguridad' en el primer plano de las preocupaciones 'de la gente'. Nadie da cuenta de la manera como se organizó el discurso y cuáles fueron los poderes fácticos que lo han transformado en una suerte de sistema global de manipulación de las conciencias, de todas las conciencias: las de los de adentro y las de los de afuera, e incluso las de los artífices del discurso. Pareciera que el discurso de la seguridad ciudadana es consustancial con el proceso de alto crecimiento económico

2

Obviamente no es éste un rasgo privativo de la identidad chilena. Podrian asumirse entre nosotros, por ejemplo, muchas de las reflexiones de RAMOS, Samuel, PAZ, Octavio y FUENTES, Carlos, cuando destacan el complejo de inferioridad, el temor reverencial ante las distintas encarnaciones de la autoridad, el sentimiento de soledad y las oscilaciones entre la humildad humillada y el orgullo insufrible, todos ellos rasgos tan úpicos del mexicano. 
sin distribución del ingreso, que ha dominado en la economia y sociedad chilenas de los últimos veinte años. Es un discurso necesario. La riqueza se ha duplicado en menos de una década, manteniéndose invariable o acrecentándose la relación de acceso a los bienes materiales entre los miembros de la sociedad. Esta es una situación explosiva. Frente a ello es preciso estereotipar a los excluidos.",22.

Se trataría nuevamente de 'patrones', sólo que ahora en medio de relaciones de profunda desconfianza. Así como el modelo capitalista global de desarrollo se nos mostraba, en verdad, como un mecanismo de dominación, así también habría que pensar que a escala nacional se reproduce la estructura de la dominación. En nuestro caso, el discurso de la modernización aparece más bien ligado a una ancestral y colonial mentalidad. Con diversas ropas, se trataría del mismo 'patrón' de siempre. Sin embargo, la cultura es uno de los campos donde la intervención deliberada es más dificultosa. ¿Qué hacer en un mundo de simbolos, tradiciones, imágenes, lenguajes, textos, ideologías, religiones, estilos, prejuicios, poderes solapados...?

En suma, los problemas de la 'modernización a la chilena' (la modernización sin modernidad) han dado origen a un sistema político-económico-cultural que no se nutre con, sino que se protege de, la deliberación colectiva, rasgo éste que es postulado como una 'virtud del sistema' por la derecha conservadora y como un 'dato de la causa' por la concertación gobernante. Ahora bien. En sentido procesal, la transición se acabó con el traspaso del poder en 1990. Pero en sentido normativo, la democratización es tarea de nunca acabar, menos aún con una democracia tan imperfecta como la nuestra. En suma, la deliberación colectiva sobre los asuntos públicos es mínima e irrelevante, y el control social sobre las autoridades, muy pobre. Simétricamente, la dominación/domesticación sobre una población atomizada y económicamente precaria hace más incierto el desarrollo democrático chileno. El error de cálculo de los negociadores concertacionistas en 1989 y de los que aprobamos dichas reformas constitucionales nos ha dejado atados de pies y manos hasta no sabemos cuándo -quizá hasta que la derecha sea mayotía

\footnotetext{
${ }^{22}$ BENGOA, José, "Desigualdad y seguridad ciudadana", en Menseje 493 (2000), pp, 52-55, Esto es lo que Gabriel Salazar ha llamado la "legitimación policial del modelo": "La llamada transiciän a la democracia ba significado, en cruda perspectiva histírica, que la dictadtra neoliberal se transformana en democracia neoliberal. El cambio ba implicado a su rez -subre todo desde el arnesto de Pinachet en l sundres- una creciente despersonalización det conflicto y ta creciente dificultad de asumir como conflictiono en sí mismo inn

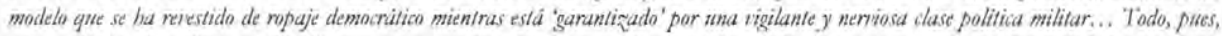

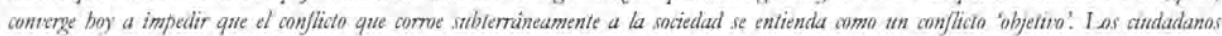
tienen que enfrentarse par si mismos, solox, individualmente, a los rigores del Merado, a la lejunia tecnocrifica del Esfado, a la calculistica ingenieria etectoral de los partidos, al rigor implacable de la llamada 'llexibilidad del emplen'. Y', sabre todo, al drama pritudo de tener que nesponder, como jefe de bogar, a tma familia que dificilmente prede permanecer unida, y a una masa de 'cabros chicas' gue fiende a fracasar en la proba del SIMCE, a deserlar del colegio y a engolfarse en actividades callejeras que, pana ellos, son, cuando menos, frentes de identidad propia, de avociatividad libre y de recursos (ilicilos a no) más accesibles que los que proporciona, en cuentagoias, al sistema labonal legalizado... No hay duda de que la 'ohjetiración policial' del conflicto social madruga o se anticipa a una posible 'objetitación política' del mismo... Pero no debe alvidarse gue et sistema neoliberal ba producido y sigtue produciendo estructuralmente las condictones que inducen subjetnamente a grandes masas de chilenos a optar por la violencia doméstica y/o delictual, por el fracaso escolar, la droga, el alcobol y la libertad callejera. La obra maestra de to que zen sociólugo llamó 'rerolición neoliberal' ba sido subjetivar el conflicto social y objetivar políficamente la necesidad sncial de la policia.": "Legitimación policial del modelo", en Mensaje 492 (2000), pp. 44-49.
} 
y se dé cuenta de que no es negocio sacar más votos pero sólo la mitad del parlamento. ¿Existe la obligación moral de emanciparse de las diversas formas de dominación o, como piensa una parte de la élite concertacionista, bastará con acomodarse a lo que hay: el presente es la mejor versión de lo posible?

\section{EPÍLOGO}

Los informes técnicos y científicos (los mismos Informes PNUD) presentan valiosos análisis y sugerencias. Pero, no se toman las cosas con filosofía, o sea, radicalmente. Y esto en varios sentidos. Primero, hay un problema en el temple con el que se enfrentan estas investigaciones, que marca un cierto télos de los investigadores: el deseo de que, al cabo de la investigación, se reconcilien los diversos elèmentos en pugna. En el caso de los Informes PNUD, modernidad y modernización. A nuestro juicio, son cuestiones enteramente distintas y, en ocasiones, antagónicas. Por ejemplo, un informe como el del PNUD de 1998 obliga a optar: los procesos de modernización en marcha, junto a sus eventuales beneficios, tienen costos (a menos que se demostrase que no hay costos sino puros beneficios). Lo demás nos pone en camino al autoengaño: ver sólo los beneficios y negar psicológicamente los costos. Abordar filosóficamente la cuestión es llevar las ideas hasta el límite, en el límite hacerse consciente de las opciones en juego, y optar. Y si hay costos, se trata de hacerlos visibles y aceptarlos conscientemente. Así, por ejemplo, puede ser pertinente la pregunta de Hopenhayn: ¿dónde centrar el goce de la vida en este escenario que se nos ofrece? Él señala algunos rasgos: el goce de la vida estaría en la extatización del cambio, en la liviandad de los lazos, en la ocupación de intersticios -pequeñas utopías al interior de un mundo desencantado-, en la apuesta por la pasión, en el gusto por las formas ${ }^{23}$. Pero, una vez más, sigue la pregunta al acecho: ¿son propicios para motivar una integración (social, nacional, latinoamericana) estos móviles del goce? ¿O hace falta una dirección más sólida, un lazo más firme? ¿De qué opción se trata? ¿Qué es lo que queremos?

Por esto, en segundo lugar, conviene abundar algo más en las relaciones de la filosofia con las ciencias y las técnicas, particularmente con técnicas y ciencias humanas y sociales. Es indiscutible la necesidad de apertura, de diálogo y de colaboración entre la filosofia, las ciencias y las técnicas; Popper, Prigogine, Zubiri y Habermas son modelos al respecto. Mas, hoy parece que los problemas y las aspiraciones nacionales no encuentran mejor elaboración que la tecno-científica. Es cosa de observar nuestro escuálido debate público; en él toman parte políticos, economistas, ingenieros, abogados, médicos, sociólogos, sicólogos, politólogos, uno

23

HOPENHAYN, Martin, Ni apocalípticos ni integrados: aventuras de la modernidad en América Latina (FCE, Stgo. de Chile 1994), pp. 29-30. 
que otro eclesiástico. El 'espíritu absoluto' brilla por su ausencia: arte, religión y filosofia suelen ser los convidados de piedra en nuestras discusiones colectivas. Y esta ausencia es peligrosa. Para Nietzsche, la filosofía tiene que ser la mala conciencia de su propia época. Sin filosofía, se corre el riesgo de que cunda el optimismo fácil. La falta de filosofía puede hacer que las ciencias se vuelvan dogmáticas, y las tecnologías, vulgares y prepotentes. De allí a los sabios-ignorantes de que hablaba Ortega no hay más que un paso:

"Para progresar, la ciencia necesitaba que los hombres de ciencia se especializasen. Los hombres de ciencia, no ella misma. La ciencia no es especialista. Ipso facto dejaría de ser verdadera...

[El especialista] es un hombre que, de todo lo que hay que saber para ser un personaje discreto, conoce sólo una ciencia determinada, y aun de esa ciencia sólo conoce bien la pequeña porción en que él es activo investigador. Llega a proclamar como una virtud el no enterarse de cuanto quede fuera del angosto paisaje que especialmente cultiva, y llama dilettantismo a la curiosidad por el conjunto del saber...

Pero esto crea una casta de hombres sobremanera extraños...

... Antes los hombres podían dividirse, sencillamente, en sabios e ignorantes, en más o menos sabios y más o menos ignorantes. Pero el especialista no puede ser subsumido bajo ninguna de esas dos categorías. No es un sabio, porque ignora formalmente cuanto no entra en su especialidad; pero tampoco es un ignorante, porque es 'un hombre de ciencia' y conoce muy bien su porciúncula de universo. Habremos de decir que es un sabio-ignorante, cosa sobremanera grave, pues significa que es un señor el cual se comportará en todas las cuestiones que ignora, no como un ignorante, sino con toda la petulancia de quien en su cuestión especial es un sabio." 24

Una reflexión similar hizo Heidegger:

"Los dominios de las ciencias están muy distantes entre sí. El modo de tratar sus objetos es radicalmente diverso. Esta dispersa multiplicidad de disciplinas se mantiene, todavía, unida gracias tan sólo a la organización técnica de las Universidades y Facultades, y conserva una significación por la finalidad práctica de las especialidades. En cambio, el enraizamiento de las ciencias en su fundamento

${ }^{24}$ ORTEG A Y GASSE'T, José, I a nebeliain de La masar (A. Bello, Stgo. de Chile 1989), pp. 143-145. 
esencial se ha perdido por completo.",25

Parece necesaria, pues, una reflexión mayor, al interior de las ciencias, sobre sus presupuestos epistemológicos, de tal modo de hacerse conscientes de las consecuencias que sus opciones tienen en vistas de la toma de decisiones técnicas y políticas. Ello puede contribuir a juicios más integradores y libres.

Si tiene razón Hegel, la actividad filosófica es constitutivamente crepuscular: como la lechuza de Minerva, sólo despliega sus alas al atardecer. La filosofía acompaña con retardo la ejecución de la existencia individual y colectiva; como reflexión, es siempre acto segundo. Sin embargo, la filosofía -con todas las mediaciones lingüísticas, sociales e históricas- se refiere a la realidad y de ella arranca. La filosofía es una actividad intelectual que puede orientar, iluminar, discernir la praxis en el mundo, tal como ya lo ha hecho en distintos momentos de la historia. Entre otras razones, porque siempre guarda una 'distancia reflexiva'

\footnotetext{
${ }^{25}$ HEIDEGGER, Martin, QQu' es metafísica? (trad. X. Zubiri, E. Fausto, B. Aires 1992), p. 40, El mismo Heidegger, luego de la Kebre, radicalizó su reflexión sobre la técnica moderna. Asi se ve en su entrevista con el semanario Der Spieget.

"HEIDEGGER:... Aún no tenemos un camino que corresponda a la esencia de la técrica.

Spiegel: Sin embargo, se le podría objetar de manera completamente ingenua: pero, equé es lo que aqui está dominado? Todo funciona. Cada vez se construyen más centrales cléctricas. Cada vez se producirá con mayor destreza. En la parte del mundo altamente tecnificado, los hombres están bien atendidos. Vivimos en un estado de bienestar. ¿Qué falta en realidad?
}

H: Todo funciona. Esto es precisamente lo inhóspito, que todo funciona y que el funcionamiento lleva siempre a más funcionamiento y que la técnica arranca al hombre de la terra cada vez más y lo desarraiga...

S: Bien. Pero ahora se plantea la cuestión: ¿puede el individuo influir aún en esa maraña de necesidades inevitables, o puede influir la filosofia, o ambos a la vez, en la medida en que la filosofia lleva a una determinada acción a uno o a muchos individuos?

H: ... Si se me permite contestar de manera breve y tal vez un poco tosca, pero tras una larga reflexión: la filosofia no podrá operar ningún cambio inmediato en el actual estado de cosas del mundo. Esto vale no sólo para la filosofía, sino especialmente para todos los esfuerzos y afanes meramente humanos. Sölo un dios pucde aún salvarnos [Nur noch ein Gott kann uns retten]. La única posibilidad de salvación la veo en que preparemos, con el pensamiento y la poesía, una disposición para la aparición del dios o para su ausencia en el ocaso...": Entrevista del Spiegel (trad. R. Rodriguez, Tecnos, Madrid 1996), pp. 70-72.

Parejos pensamientos aparecen en su conferencia Gelassenheit: "Podemos usar los objetos técnicos, servirnos de ellos de forma apropiada, pero manteniéndonos a la vez tan libres de ellos que en todo momento podamos desembarazarnos [loslassen] de ellos. Podemos usar los objetos tal como deben ser aceptados. Pero podemos, al mismo tiempo, dejar que estos objetos descansen en sí, como algo que en lo más intimo y propio de nosotros mismos no nos concierne. Podemos decir 'si' al inevitable uso de los objetos técnicos y podemos a la vez decirles 'no' en la medida en que rehusamos que nos requieran de modo tan exclusivo, que dobleguen, confundan $y$, finalmente, devasten nuestra esencia... Quisiera denominar esta actitud que dice simultáneamente ' $s 1^{2} \mathrm{y}$ ' $\mathrm{no}$ ' al mundo técnico con una antigua palabra: la Serenidad [Gelassenheit] frente a las cosas... Rige así en todos los procesos técnicos un sentido que reclama para sí cl obrar y la abstención humana [Tun und Lassen], un sentido no inventado ni hecho primeramente por el hombre... El sentido del mundo técnico se oculta. Ahora bien, si atendemos, continuamente y en lo propio, al hecho de que por todas partes nos alcanza un sentido oculto del mundo técnico, nos hallaremos al punto en el ámbito de lo que se nos oculta y que, además, se oculta en la medida en que viene precisamente a nuestro encuentro. Lo que así se muestra y al mismo tiempo se retira es el rasgo fundamental de lo que denominamos misterio. Denomino la actitud por la que nos mantenemos abiertos al sentido oculto del mundo técnico la apertura al misterio... La Serenidad frente a las cosas y la apertura al misterio se pertenecen la una a la otra. Nos hacen posible residir en el mundo de un modo muy distinto. Nos prometen un nuevo suelo y fundamento sobre los que mantenernos y subsistir, estando en el mundo técnico pero al abrigo de su amenaza,": Serenidad (trad. Y. Zimmermann, Odós, Barcelona 1994), pp. 26-28. No es el momento para discutir estas ideas. 
respecto de la vida cotidiana y del quehacer científico y técnico. La filosofía custodia una riqueza que no tiene precio: cierto silencio, cierta ironía, cierta responsabilidad. 